\title{
Systemic Lupus International Collaborating Clinics Classification Criteria
}

National Cancer Institute

\section{Source}

National Cancer Institute. Systemic Lupus International Collaborating Clinics Classification

Criteria. NCI Thesaurus. Code C121337.

A validated revision of American College of Rheumatology (ACR) criteria for systemic lupus erythematosus with extension to seventeen criteria. Intended to be used as inclusion criteria for clinical studies, if the patient has biopsy-proven lupus nephritis with antinuclear antibodies (ANA) or anti-dsDNA, or the patient satisfies four of the criteria, including at least one clinical and one immunologic criterion. 